\title{
MILTON HATOUM E A FICÇÃO BRASILEIRA CONTEMPORÂNEA
}

\section{MILTON HATOUM AND CONTEMPORARY BRAZILIAN FICTION}

Dayane de Oliveira Gonçalves ${ }^{1}$

Mônica Gama²

\begin{abstract}
RESUMO: Quais sáo os traços mais percebidos e valorizados pela crítica e como isso constrói uma certa expectativa de leitura para as obras estreantes? Por mais que os críticos que trabalham com a literatura contemporânea sejam praticamente unânimes quanto à variedade de propostas ficcionais, as tentativas de compreensâo da prática literária deixam entrever determinados valores e mecanismos de recepçâo das obras. A partir de duas críticas a Relato de um certo Oriente (1989), de Milton Hatoum, no momento de seu lançamento, realizadas por Flora Süssekind e Silviano Santiago, investigamos como alguns pressupostos constroem uma avaliaçâo deceptiva. A decepçâo diz respeito sobretudo a uma percepçấo de que a obra de Hatoum nâo efetuaria rupturas essenciais com a prosa modernista, aspecto mais acentuado como problema na crítica pós-moderna de Silviano Santiago.
\end{abstract}

PALAVRAS-CHAVE: Milton Hatoum; recepção; modernismo; memória; Flora Süssekind; Silviano Santiago.

\begin{abstract}
What are the characteristics most perceived and valued by critics and how does this build a reading expectation for an author's first novel? Although critics of contemporary Brazilian literature are almost unanimous regarding the variety of fictional proposals, the ways of understanding literary practice reveal the values and mechanisms of reception of literary works. From two criticisms of Milton Hatoum's Relato de um certo Oriente (1989), made at the time of its release, written by Flora Süssekind and Silviano Santiago, we investigate how some assumptions construct a disappointed rating. The disappointment refers mainly to a perception that Hatoum's work would not effect essential breaks with modernist fiction, this aspect is more accentuated as a problem in Silviano Santiago's postmodern criticism.
\end{abstract}

KEYWORDS: Milton Hatoum; reception; modernism; memory; Flora Süssekind; Silviano Santiago.

1 Mestranda em Letras pelo Programa de Pós-graduaçăo em Letras da Universidade Federal de Ouro Preto (UFOP).E-mail: doliveirag@outlook.com

2 Professora de Teoria da Literatura e Literatura Brasileira na Universidade Federal de Ouro Preto - UFOP, Doutora em Literatura Brasileira pela Universidade de Sáo Paulo - USP (2013) e Mestre em Língua e Literatura Francesa também pela USP (2008). Foi pesquisadora residente na Fundaçăo Biblioteca Nacional -FBN (2013-2015).E-mail: gamamonica@gmail.com 
"Cada linguagem é uma tradiçăo, cada palavra, um símbolo compartilhado; é irrisório o que um inovador é capaz de alterar." (Borges, 2008, p. 9)

Desde o seu romance de estreia Relato de um certo Oriente (1989), Milton Hatoum vem sendo bem recebido, năo só pela crítica especializada, mas também pelo grande público. A fortuna crítica do autor se expandiu com a publicaçăo de Dois irmáos (2000) e em seguida Cinzas do Norte (2005) e, dos comentários críticos nos cadernos de cultura dos jornais e revistas, on-line ou impressos, às análises minuciosas em âmbito acadêmico (inclusive com teses e dissertaçôes), a prosa de Hatoum foi exaltada. Entre os nomes que o aplaudiram, destacam-se alguns bastante reconhecidos como os de Leyla Perrone-Moisés, Davi Arrigucci Jr., Benedito Nunes, Luiz Costa Lima, Alfredo Bosi entre outros.

Sobretudo por se tratar do primeiro romance de um escritor até entăo desconhecido, nâo significou pouco que Relato de um certo Oriente já tenha chegado às livrarias com a qualidade estética atestada por Davi Arrigucci Jr., em paratexto bastante elogioso. Neste, o crítico diz se tratar de um romance "tramado com calma e sabedoria pela mâo surpreendente de um jovem escritor" e o avalia como prosa fascinante e evocativa, "traçada com raro senso plástico e pendor lírico" (Arrigucci Jr., 2004, n.p.).

Luiz Costa Lima, saudando-o como "um dos grandes ficcionistas do final do milênio" (Costa Lima, 2002, p. 317), sentencia que Hatoum, ao fazer com que Manaus nâo seja simples cenário para sua ficçâo, "consegue o que se configura em escritores do Sul norte-americano - desde logo, em Faulkner - e do chamado terceiro mundo: a narrativa deste espaço sociocultural, sem ser causalmente determinada, năo se confunde com a recente narrativa europeia e norte-americana" (Costa Lima, 2002, p. 317).

É, em certa medida, no sentido contrário, entâo, que duas “críticas de momento" - de Flora Süssekind (na Folha de S. Paulo): "Livro de Hatoum lembra jogo de paciência" e a de Silviano Santiago (Jornal do Brasil): "Autor novo, novo autor" apresentam-se como destoantes na recepçăo de Hatoum.

Nâo se pode afirmar categoricamente que as leituras críticas publicadas naquele mesmo sábado de 1989 a respeito do Relato de um certo Oriente sâo críticas meramente negativas. Süssekind, por exemplo, explicita a sua satisfaçấo em encontrar no romance de Hatoum uma prosa que deixa de lado "velhos "tópoi" (homem versus natureza, seringueiros e descritivismos) da literatura regionalista amazônica" (Süssekind, 1989, n.p.)․․ Ela também năo deixa de notar o imenso esforço técnico a que o autor se submete logo no primeiro livro, aproximando a sua estruturaçăo romanesca à de As Ondas, de Virgínia Woolf, e de O som e a fúria, de William Faulkner, ainda que veja no projeto ficcional de Hatoum algumas falhas (Süssekind, 1989).

3 Vale lembrar que em Tal Brasil, qual romance? (1982), a crítica propóe o mapeamento de situaçóes de reaparecimento da estética naturalista na literatura brasileira, para, entāo, melhor exaltar, por oposiçâo, a qualidade literária dos casos desviantes, o que em alguma medida explica a sua satisfaçâo, nesses termos, com a prosa de Hatoum. 
Silviano Santiago, do mesmo modo, năo se abstém em exaltar o que se apresenta a ele como digno de elogio. Para ele, sâo fascinantes as três formas de descentramento com as quais o romance trabalha. $O$ descentramento espacial, com a narrativa em Manaus; o descentramento quanto à forma de "investigaçáo vertical no tempo", que surpreende por nâo se ocupar da "constituiçăo da nossa sociedade pelo índio massacrado, a colonizaçăo portuguesa, o trabalho negro ou a imigraçâo europeia", mas da "história de sucessivas geraçōes de uma família libanesa no Brasil" (Santiago, 1989, p. 5). E, por fim, o descentramento de perspectiva narrativa: a narradora, ao mesmo tempo pertencente e náo pertencente à família (adotada pela matriarca Emilie), oferece um ponto de vista que proporciona uma visada à família a partir de um "sutil jogo de dentro/fora" (Santiago, 1989, p. 5).

Porém, em comum, as duas críticas guardam um certo incômodo com a resoluçăo final encontrada pelo autor para justificar o fato de que uma variedade de narradores tenha a mesma dicçâo narrativa. Para Flora, essa saída "acaba forçando o romance a se auto-explicar no final, a avisar, de modo quase didático, o que já ficara claro para o leitor: que a voz é uma só [...]" (Süssekind, 1989, n. p.). O mesmo problema é percebido por Silviano Santiago como sendo uma "falsidade psicológica ao nível do tratamento da linguagem", e, assim como Flora, o crítico incomoda-se com o recurso final que o autor utiliza: "Milton Hatoum tenta desesperadamente matar o defeito na última página do livro, embora o leitor tenha convivido com o defeito durante toda a leitura" (Santiago, 1989, p. 6).

Os incômodos de Santiago năo se encerram aí; e, mais do que isso, náo é esse citado problema o que mais parece lhe incomodar na produçáo deste "autor novo" ou "novo autor". Para esse crítico-escritor, o livro, especialmente a sua forma memorialista, permanece muito marcadamente preso à estética modernista, em particular a dos anos 1930. Tal crítica se conecta à advertência de que a literatura contemporânea deve se desvincular da estética modernista - desejo expressamente declarado em seu ensaio "Fechado para balanço", de 1982, e também em outros".

\section{"PERFUME ADOCICADO" DA MEMÓRIA: CONTINUIDADE E REPETIÇÃO EM HATOUM}

Está em Nas malhas da letra (2002) o ensaio de Silviano Santiago em que mais se evidencia uma demanda de ruptura na nova prosa brasileira. Esta năo é correspondida por Relato de um certo Oriente, o que parece reger de forma velada a sua crítica no Jornal do Brasil, a partir de um pressuposto que, entāo, na crítica, náo se apresenta declaradamente: a defesa de uma estética pós-moderna.

"Fechado para balanço", datado de 1982, foi escrito, portanto, na ocasiăo do sexagésimo aniversário do movimento modernista brasileiro. Assim, grande parte do ensaio se ocupa centralmente dos ciclos de interpretaçâo do período modernista,

4 Outros ensaios do autor, como "A permanência do discurso da tradiçáo no modernismo", evidenciam uma mesma urgência de ruptura com a estética modernista. 
em que se procede a uma análise que, para além do valor da produçâo literária do período, estende-se a problematizaçôes extratextuais, como a complexa relaçâo mantida entre os artistas do período e o Estado Novo. No entanto, aqui importa-nos menos este mapeamento revisionista dos três ciclos modernistas do que a tese a que o crítico chega: a de que um esgotamento das interpretaçóes do movimento impedia a sua continuidade e levava à necessidade de que este se desse, definitivamente, por encerrado:

Nâo se pode continuar soprando as velas de um bolo - ontem com cinqüenta e hoje com sessenta - e acreditar que se está comemorando um batismo de um bebê. A questâo é a seguinte: de que maneira a estética do romance modernista gera hoje, para um jovem escritor brasileiro, armadilhas artísticas e ideológicas de que ele deve se liberar, para que corte de uma vez por todas o cordăo umbilical que ainda o prenderia a esses "mestres do passado" para usar a gloriosa expressăo de Mario de Andrade em contexto passado e semelhante. (SANTIAGO, 2002, p. 86)

Nesse ensaio, Santiago orienta seu olhar para o futuro da literatura brasileira e manifesta um desejo de "novidade", de ruptura com o status quo, que deveriam constar nas pautas do novo romancista. Ao se posicionar em uma situaçấo que seria - guardadas as devidas proporçōes - paralela à de Mario de Andrade, em alusâo clara ao momento de insurgência do modernismo, Silviano Santiago advoga em nome de um projeto literário novo, a favor de uma liberaçăo da estética modernista, tal qual foi necessária aos escritores (e artistas, de modo geral) do modernismo uma forte cisâo com a tradiçấo que o precedeu. A este projeto literário "novo" Silviano Santiago chama "pós-moderno".

É certo que năo se pode simplificar demasiadamente a questăo, pois a ocorrência do paralelismo nâo é, em absoluto, simétrica. A definiçăo de uma estética "pós-moderna" é, ainda hoje, alvo de muitas confusōes e conflitos. Convencionou-se chamar assim uma vertente da prosa muito presente na literatura brasileira da década de 1980 (um movimento estético que vem depois da modernidade e a ela se opóe), cujos preceitos estavam relacionados à substituiçăo do código modernista por movimentos plurais que, em geral, propunham uma fricçâo entre as dicotomias tradiçăo e inovaçăo, conservaçăo e renovaçăo, cultura de massa e cultura erudita. O que se observa - no entanto e náo raramente - é um uso sinonímico entre "contemporâneo" e "pós-moderno", o que corresponde a um grande problema, porque nem toda prosa contemporânea satisfaz ao ideário de uma estética "pós-moderna" - como é o caso da literatura de Milton Hatoum. Assim, principalmente no terreno da estética, o conceito continua bastante impreciso. No que diz respeito à literatura, as características apontadas como sendo próprias do pós-moderno sâo pouco satisfatórias no convencimento de que há algo, de fato, próprio a ela.

Santiago, contudo, deixa suas pistas: o prefixo "pós" náo estaria ligado a uma noçâo temporal linear de evoluçáo literária, mas a uma evoluçâo que, em conformidade com os formalistas russos, dar-se-ia pelo deslocamento de forças. A ruptura proposta por Silviano, portanto, năo direciona o jovem romancista ao rompimento com o passado literário simplesmente; ao contrário disso, aponta como possível caminho a ligaçâo com uma "tradiçăo-sem-tradiçăo": 
[...] este percurso, porque escapa ao fechamento do modernismo que estamos propondo, pode funcionar como instigante facăo para uma futura releitura do movimento. Levemos em consideraçăo dois autores que têm sido bastante negligenciados pela tradiçăo modernista e que, a meu ver, estăo constituindo um bom repertório para a contestaçăo atual da estética originada em 22 , e, ao mesmo tempo, representam uma saudável mudança de ares para o jovem romancista [...] Penso, em particular, em Euclides da Cunha e em Lima Barreto. Ambas as figuras aparecem, dentro das histórias da literatura, no movimento que se convencionou chamar de "pré-modernismo". Talvez o verdadeiro "pós" possa se nutrir convenientemente do "pré", e năo do modernismo propriamente dito. (SANTIAGO, 2002, p. 101)

Da mesma forma que o prefixo "pós", o prefixo "pré", muito mais do que mero demarcador temporal, acentua o sentido de distinçâo em relaçăo ao modernismo, o que possibilitaria tomar como pontos de partida elementos da obra tanto do Euclides da Cunha quanto Lima Barreto sem que isso configurasse continuidade das interpretaçôes dos ciclos modernistas. Sendo assim, Santiago revaloriza na obra dos escritores tais elementos que os mantiveram fora dos padróes estéticos e ideológicos estabelecidos pela estética modernista.

Em Lima Barreto, é destacado o uso da "redundância" em contraposiçăo à "elipse" (que seria própria da estética modernista). O uso que Lima Barreto faz desse traço estilístico com precisâo absoluta e rigor crítico, conforme assegura Santiago, produziria no texto a idêntica dose de densidade e instigaçâo que na escrita modernista seria originada pela elipse.

Já em Euclides da Cunha, o que é elogiado pelo ensaísta é a sua postura crítico-reflexiva. Sem deixar-se cair na armadilha que seria a adoçăo do discurso elogioso e indiscriminado à República, perigo que se assimilaria em grau a uma postura monárquica, a coragem de Euclides faz-se dupla. Política, à medida que denunciava a carnificina de Canudos efetivada pelas tropas republicanas; e intelectual, à medida que colocava em xeque os esquemas de pensamento de sua época.

Em suma, Santiago destaca que a grande liçáo deixada ao jovem ficcionista é de "uma escrita popular, ao mesmo tempo, crítica" por Lima Barreto; e "um saber que, ao se desvincular do autoritarismo inerente ao grupo que o detém e a si mesmo, volta os olhos para os vencidos, enxergando neles uma verdade que escapa às diretrizes excludentes da modernizaçăo" (SANTIAGO, 2002, p. 106-7) no caso de Euclides da Cunha.

Poderíamos chamar a atençăo também para outros traços da escrita de Lima Barreto caras ao escritor contemporâneo: a prosa realista e crítica quanto às configuraçôes sociais, a inscriçâo de um eu (tomada muitas vezes pela crítica como um defeito, já que a questăo racial seria sempre a marca de um sujeito ressentido), a percepçấo acurada da urbes e dos lugares de exclusăo, a percepçăo crítica da literatura como objeto simbólico e de consumo entre outros.

Ainda, no ensaio "Prosa literária atual no Brasil", de 1984, Silviano Santiago propóe uma compreensăo panorâmica da criaçâo literária brasileira entre as décadas de 1970 e 1980, apontando linhas de força, temáticas e formais, mas sempre considerando em que medida esses novos projetos literários se vinculavam e se distanciavam da estética modernista das décadas precedentes. 
À dificuldade de classificar as propriedades do romance daquele momento o crítico atribui ao fato de que nossa literatura estaria vivendo um período de "transiçấo literária" - aludindo à fase que sucede ao que ele considerava, entấo, como o esgotamento do período modernista. Torna-se próprio desse momento de transiçâo a implosâo das regras que até entâo eram tradicionais, já que se busca por modelos que melhor se conjugassem aos novos anseios e necessidades. Por conseguinte, seu mapeamento acaba por apontar para um certo caráter de "anarquia formal" do romance brasileiro a partir da década de 1970, característica que se distingue, por exemplo, dos romances da Geraçáo de 30, os quais seguiram, em alguma medida, uma convençấo compartilhada entre os seus prosadores no que diz respeito às regras de composiçăo.

Longe de ser um defeito, essa "anarquia formal" apontada por Santiago seria, ao contrário, responsável por deixar mais livre o romancista no uso de sua potencialidade criativa, cabendo a este a escolha de um molde que melhor se ajustasse às novas situaçóes dramáticas e a escolha de uma determinada dicçăo narrativa. No entanto, reconhece um ponto de acordo entre a maioria dos prosadores: uma tendência ao memorialismo ou à autobiografia. A preocupaçăo memorialista é uma evidente inscriçăo na tradiçăo da prosa modernista, mas dessa vez se trataria de um encontro com as raízes do gênero para entâo readaptá-lo à atualidade brasileira. Assim, a partir de 1970 essa tendência se voltava para uma ambiçáo de "conscientizaçâo política" do leitor e de uma explicitaçăo mais radical da veia autobiográfica, "deixando ainda mais abaladas as fronteiras estabelecidas pela crítica tradicional entre memória afetiva e fingimento, entre as rubricas memórias e romance" (Santiago, 2002, p. 35), o que resultou em que se tornasse a "tônica da época" uma prosa cuja espinha dorsal teria se deslocado "do fingimento para a memória afetiva do escritor, ou até mesmo para a experiência pessoal" (Santiago, 2002, p. 36).

Com o retorno dos exilados políticos, impôs-se a narrativa autobiográfica. Este modelo insurgiu com a experiência guerrilheira, mas logo teve seus limites extrapolados e frutificados pela "via da marginalizaçaăo": "o fenômeno da marginalizaçăo é compreendido como uma espécie de exílio interno: trata-se de determinados grupos sociais que eram e săo desprovidos de voz dentro da sociedade brasileira, cuja voz era e é abafada" (Santiago, 2002, p. 40).

Para Santiago, a principal diferença entre esse memorialismo dos exilados e o dos modernistas - que estaria mais ligado a uma "linhagem proustiana" (narraçăo a partir da inércia do protagonista narrador) seria a oposiçăo criada por um relato narrado a partir da experiência ativa, própria, vivida e sofrida do narrador-personagem, marcando, assim, uma urgência de enunciaçăo.

Portanto, assumir esses dois ensaios de Santiago como pano de fundo da crítica a Relato de um certo oriente torna mais evidente a natureza do nítido desapontamento que o crítico deixa transparecer em relaçáo a esse primeiro romance de Milton Hatoum.

Relato de um certo Oriente - muito mais inclinado aos valores modernos do que aos "pós-modernos" - passa ao largo do projeto da historiografia metaficcion- 
al, náo toma de forma evidente e central como tema nenhum problema do passado político nacional, abusa da elipse como recurso estilístico e em muito dialoga com o "modelo memorialista proustiano", incluindo o uso de "gatilhos de memória" como acionadores de uma "memória involuntária".

Além disso, se nesse romance o diálogo é mais evidente, nos outros dois seguintes a ligaçáo ainda é encontrada, à medida que os três giram em torno da busca por algo que se perdeu, o que é sempre uma missăo fadada ao fracasso: algumas memórias estâo para sempre perdidas, alguma certeza objetiva será sempre inalcançada, o tempo passado, reconstruído tâo fragmentadamente pelas memórias possíveis, está para sempre perdido. Esta busca é, visivelmente, herdeira do emblemático empreendimento proustiano.

Enfim, “o perfume adocicado de "escrita da memória"'" (Santiago, 1989, p. 5) tanto aborrece Santiago, porque parecia a ele algo absolutamente saturado. Aliás, perspicaz é a sua apropriaçăo do senso comum de que um perfume doce é nauseante e enjoativo na elaboraçáo de seu eufemismo crítico. No entanto, a recepçáo de Relato pelo campo literário tanto quanto dos seguidos romances parecem corroborar uma tese diferente desta saturaçáo ou do efeito fastidioso provocado pela forma.

Cabe dizer, ainda, que se admitimos uma estética pós-moderna, à revelia da imprecisâo que lhe concerne, devemos entâo manter o cuidado em nâo fazer uso sinonímico entre contemporâneo e pós-moderno, sobretudo quando se é pensado simplificadamente que uma estética pós-moderna é aquela que, no Brasil, é a sucessora (temporal) do modernismo. Os romances de Milton Hatoum sâo provas de que nem toda produçâo contemporânea, posterior ao modernismo literário, é pós-moderna; nem por isso, contudo, seria justo classificá-la como velha literatura de um novo autor, conforme deu a entender Santiago em sua crítica de 1989. Afinal, verifica-se nos romances de Hatoum valores modernistas, sem que, no entanto, estes deixem de guardar com a estética do movimento suas diferenças, o que o próprio Silviano reconhece, por exemplo, ao numerar os descentramentos promovidos pela obra.

\title{
RUÍNAS DA MEMÓRIA, RUÍNAS DA MODERNIDADE
}

\author{
“O passado só se deixa capturar como imagem que relampeja irreversivelmente no \\ momento de sua conhecibilidade" \\ "Articular historicamente o passado náo significa conhecê-lo "tal como ele de fato \\ foi". Significa apropriar-se de uma recordaçăo, como ela relampeja no momento do \\ perigo" (Benjamin, 2012, p. 243)
}

É, portanto, pensando-se nesse intervalo que ocupa a literatura de Milton Hatoum - nem modernista, tampouco pós-moderna -, que se faz importante capturar algumas particularidades do seu projeto literário no que diz respeito à negaçáo de um passo à frente, que seria o da assunçấo da entâo - exigida por alguns - estética pós-moderna. 
Há nos romances de Milton Hatoum uma preocupaçăo em tornar forma e conteúdo indissociáveis que talvez seja um de seus valores mais notáveis. É bastante explorada entre os estudiosos - o que se observa na fortuna crítica constituída do autor - essa indissociabilidade em relaçâo à memória, espécie de "deusa tutelar" dos seus romances. Do ponto de vista temático, a memória faz-se grande protagonista. Seus três primeiros romances tematizam uma "memória de família" - e năo apenas; há, entremeadas, outras tantas memórias, como uma memória coletiva.

Maurice Halbwach (1950) define a memória coletiva em contraposiçăo ao que seria uma "memória histórica" - grosso modo, a história dos manuais, oficial, institucionalizada, interpretaçáo de fatos organizados sequencialmente de forma artificial. Assim, a memória coletiva, por sua vez, seria "viva", "orgânica", passada de uma geraçấo a outra e sobrevivente enquanto estiver ativa a sua transmissăo. Nesse sentido, os romances de Hatoum guardam também uma dimensăo de memória coletiva (ficcionalizada), quando dâo voz tanto a descendentes de imigrantes, com suas identidades híbridas e mestiças que se opóem a uma "identidade nacional pura" (sendo assim, uma literatura que se afirma dentro de um espaço de oposiçăo ao longo discurso da nacionalidade, que pretende uma identidade nacional una e homogênea), quanto a um grupo ainda mais marginalizado e esquecido pela história: caboclos e indígenas da regiâo do Amazonas, pobres e silenciados. Tal situaçăo se evidencia, sobretudo, na figura de Anastácia Socorro, em Relato, e Domingas, em Dois irmáos - ambas personagens agregadas, exploradas, ocupantes de um lugar social limítrofe entre o trabalho livre e o escravo. Desse modo, se a literatura de Hatoum năo apresenta o engajamento político imediato e direto esperado por alguns teóricos do contemporâneo, tampouco pode ser acusada de năo ser uma literatura crítica e ética, isto é, que náo se amplia para além da sua funçâo estética.

No que diz respeito às famílias tematizadas em cada romance, é certo que elas guardam além de semelhanças - sobretudo as de Relato e Dois Irmâos, formada por imigrantes libaneses estabelecidos em Manaus - grandes diferenças constitutivas; mas, em maior ou menor medida e por razóes que variam em cada caso, faz parte dos três enredos a vontade de memória que vai se efetivando pelo narrador. Cercado por ruínas, este recolhe e agrupa os fragmentos, vestígios e estilhaços do passado. Cada um dos romances revela uma demanda/urgência específica que serve de mote às buscas, mas, de modo geral, essas aspiraçóes săo as que justificam a fixaçáo dos narradores em reconstruir, da forma mais completa possível, a partir das reminiscências próprias e de terceiros, uma imagem do passado que só pode ser fragmentada e lacunar.

Assim sendo, também nos seus três primeiros romances, cada um à sua manei$\mathrm{ra}$, as arquiteturas narrativas săo moduladas pelo grande tema e, por isso, encenam o funcionamento vertiginoso da recordaçăo, grosso modo, essa faculdade responsável năo apenas pela nossa capacidade de recordar, mas também de esquecer. Consegue-se tal efeito estilístico, justamente, por meio das técnicas da narrativa memorialista moderna, herdadas, em alguma medida, do "modelo proustiano": informaçăo narrativa fragmentada, parcial; sequência narrativa năo linear entre outros recursos. A náo utilizaçăo de um tempo cronológico linear, por exemplo, é 
fundamental na realizaçâo de um efeito que imita esse caráter lacunar e desordenado das lembranças; nesse sentido, năo por acaso as três narrativas se iniciam, justamente, em um tempo da diegese que, se organizado cronologicamente, equivaleria ao seu final.

Percebe-se, assim, uma ligaçăo intrínseca entre ruínas e memória. "Ruínas" comporta uma significaçâo dupla: uma mais usual e dicionarizada, relacionada a destroços, a um estado de destruiçâo e decadência; a outra, originada do desenvolvimento do conceito de ruínas por Walter Benjamin ${ }^{5}$.

Essa acepçăo carrega semanticamente a ideia de ruína como o que sobreviveu do todo que ruiu; é um resto, um fragmento significativo, que transporta e mantém o legado do que nâo existe mais porque se desfez. Ora a primeira acepçâo, ora a segunda, ora simultaneamente as duas se presentificam na obra de Hatoum. Náo por acaso, assim como a memória, as ruínas, e năo raro as ruínas como alegoria da memória, săo frequentemente lembradas na fortuna crítica do autor ${ }^{6}$. Os três primeiros romances de Hatoum ainda abrangem a alegoria das ruínas associada à casa familiar, ao espaço amazônico, ao desenvolvimento e modernizaçăo urbana de Manaus, à identidade das personagens entre outros.

Ressaltamos, por fim, outra relaçâo guardada entre a obra ficcional de Milton Hatoum, memória e ruínas (na acepçăo benjaminiana do termo). Trata-se năo mais de uma questâo de memória na literatura, mas de memória da literatura, à medida que o seu projeto literário é composto em grandes proporçōes das ruínas da modernidade, isto é, na intensa relaçâo com a tradiçâo literária.

Um ponto de vista bastante dissonante do de Silviano Santiago na análise da produçấo literária contemporânea é o de Leyla Perrone-Moisés. Em Mutaçóes da literatura no século XXI (2016), a autora aborda a literatura a partir da década de 1990, sem se limitar à literatura brasileira. Algumas discussōes de Mutaçôes dâo continuidade a questôes que já começavam a ser tratadas em "Modernidade em ruínas", último capítulo de Altas literaturas (1998). Uma destas se refere à sua tese de que após um período de apogeu (no Brasil, o modernismo) acentuou-se um certo desprestígio da literatura. Uma das justificativas para isso seria o fato de que o "aspecto estético tem perdido terreno em decorrência da banalizaçâo do conceito de "literatura" (Perrone-Moisés, 2016, p. 19). Se para a "pós-modernidade literária" - como fazem questăo alguns de chamar, entre eles Silviano Santigo -, iniciada no Brasil na década de 1980, além do engajamento político necessário no fortalecimento da redemocratizaçâo, uma outra questâo pautada teria sido a preocupaçâo com a profissionalizaçâo do autor, o que envolvia transformar o livro em bem de consumo, entăo, para Perrone-Moisés o espectro da qualificaçăo pós-moderna está no cerne dessa perda de terreno do aspecto estético.

5 O signo das ruínas é desenvolvido na obra de Walter Benjamin, nas teses "Sobre o conceito de história", mas, sobretudo, em "Alegoria e drama barroco", em Origem do drama barroco alemâo.

6 A dissertaçăo “A ficçâo em ruínas: Relato de um certo Oriente, de Milton Hatoum”, de autoria de Denis Leandro Francisco, busca evidenciar como o texto literário de Hatoum realiza, temática e estruturalmente, uma apresentaçăo de suas insuficiências e instabilidades. 
Para ela, corresponde a um equívoco tanto julgar a obra literária pelo gosto ou em termos de consumo, vendagem e publicidade quanto considerar um texto como literatura pelo seu valor político - o que se trata de uma atitude ética, mas năo estética. Assim, defende que independentemente da proveniência ou da temática, um texto merece ter a sua qualidade atestada pela força da sua linguagem, pela capacidade de provocar emoçăo, entre outros; isto é, por sua potencialidade estética. Essa defesa, no entanto, náo implica que o viés político/ético deva ser renunciado na produçấo literária, mas apenas que o valor ético năo deve se sobrepor ou anular o valor estético. A questăo culmina, entấo, na proposta de Habermas, a que Perrone-Moisés faz mençẫo em "Modernidade em ruínas": o filósofo propóe que o caminho deve se dar pela "interaçăo livre dos elementos cognitivos com os prático-morais e os estético-expressivos", isto é, como bem traduz Perrone-Moisés, "revincular o conhecimento com a ética e a estética: reexaminar o projeto moderno para verificar os pontos em que ele emperrou e levar adiante aquelas de suas propostas que ainda têm futuro" (Perrone-Moisés, 1998, p. 182).

Assim, o posicionamento de Perrone-Moisés se opóe frontalmente ao de Santiago no que diz respeito à relaçăo que um e que outro nutrem com o que seria uma literatura "pós-moderna". Para Perrone-Moisés, é inegável que mudanças tantos tecnológicas quanto culturais ocorridas afetaram a literatura, mas o que se vê é "menos uma liquidaçấo da modernidade do que sua assimilaçăo numa postura irônica, e uma exacerbaçăo de procedimentos existentes, há muito tempo, nas obras literárias", de modo que se a chamada literatura pós-moderna tiver uma peculiaridade, esta consistiria, para ela, em "nutrir-se da modernidade, numa atitude consumista que é própria de nosso tempo" (Perrone-Moisés, 2016, p. 45).

Perrone-Moisés năo prescinde de que as principais formas que assume a literatura contemporânea săo dependentes de um passado recente, em oposiçấo à constataçáo de propostas de criaçăo inovadoras. Daí resulta o seu ponto de vista que é carregado um tanto de uma certa melancolia: "o sentimento de existir depois do fim, de ser uma literatura que năo é de vanguarda, mas tardia"7. A sua avaliaçâo é que, assim como na política, na economia, nas esferas sociais de um modo geral, "a literatura vive um interregno, aquele momento em que as regras antigas já năo existem e outras, na melhor das hipóteses, ainda estâo em gestaçăo" (Perrone-Moisés, 1998, p. 149).

Portanto, entre as visadas ao contemporâneo de Santiago e Perrone-Moisés, é evidente que o projeto literário de Hatoum parece se ajustar mais ao espírito de uma "modernidade em ruínas", o que significa se assumir, de forma conscienciosa, nesse lugar da năo vanguarda; como "tardio", nos fins. E, embora Silviano Santiago

7 Como apontamos, Leila Perrone-Moisés vai mostrando que uma série de características tomadas como inovaçôes, como a aboliçăo dos gêneros literários na prática de gêneros híbridos, săo, na verdade, a intensificaçâo de projetos que já estavam em curso. É o caso do traço da intertextualidade, por exemplo: citaçôes, pastiches, paródias e outras formas de metaliteratura que sempre foram praticados pelos escritores, pois a literatura sempre nasceu da literatura anterior e dela se alimentou. O que é novo, na literatura contemporânea, é a existência de livros que se nutrem quase que exclusivamente de obras anteriores, de livros que ficcionalizam a própria literatura ou a biografia dos escritores canônicos. (Perrone-Moisés, 2016, p. 260) 
se resguarde em bem explicar o "pós" do seu desejo de uma estética "pós-moderna" (nâo como evoluçâo linear literária), nâo está implícita na valorizaçăo da novidade, assim mesmo, uma ideia de continuidade e de progressâo na história literária?

Assumir-se tardio significa que a literatura de Hatoum recusa o passo ao "pós-moderno", sem a ilusăo de que ainda haja tempo para ser modernista. É certo que alguns podem ver nisso uma atitude covarde; mas, de outro ponto de vista, é valorosa a humildade de quem reconhece que nâo apenas de excepcionalidades é feita a história da literatura e que o recuo é, algumas vezes, mais honesto do que o alarme falso da novidade. Que os romances do autor năo inovem e continuem acenando à tradiçâo literária seja um fato, outro é que, por isso também, eles nâo caem em experimentalismos artificiais, meros exercícios estilísticos. Isto é também reconhecido por Alfredo Bosi ao se referir à prosa de Hatoum:

um certo ideal de prosa narrativa, refletida e compassada, que vem de Graciliano e chegou a Osman Lins, năo é forçosamente fruto de um passado estético irreversível. Esse padrăo resiste em meio aos cacos do mosaico pós-moderno e significa a vitalidade de um gosto literário sóbrio que năo renuncia a mediaçăo de uma sintaxe bem comportada e do léxico preciso. (BOSI, 1974, p. 437)

Hatoum nâo deixa para segundo plano a preocupaçăo formal e póe as possibilidades do regime narrativo em serviço da fábula. Năo basta uma boa história, há que saber contá-la bem. Para fazê-lo, o "leitor Milton Hatoum" năo se divorcia do "escritor Milton Hatoum". Tâo cara a ele é a noçâo de literatura como herança, assume a responsabilidade de ter às costas a tradiçâo. Seu projeto literário é concebido, assim, como um sistema de relaçôes e se nutre, orgulhosamente, da fertilidade das ruínas da modernidade: uma centelha que lampeja em seus romances e pôe em movimento a sua escrita.

\section{CONSIDERAÇÕES FINAIS}

A crítica de Silviano Santiago náo se equivoca quando aponta em Relato de um certo Oriente a sua ligaçáo com a tradiçăo literária modernista. O que, no entanto, nâo se parece um consenso é que essa característica - que se evidencia no seu romance de estreia e permanece no prosseguimento de sua obra - seja necessariamente um defeito. Os romances seguintes só vieram a reafirmar um projeto literário em que o consciente e desejoso diálogo com a tradição narrativa - nâo só a Ocidental e náo só o modernismo brasileiro - e o cuidado estético-formal fazemse muito mais característicos da prosa de Hatoum do que uma pretensâo de novidade, de vanguardismo, de experimentalismos narrativos, de ruptura, superaçâo ou oposiçâo à estética modernista.

Assim, se a literatura de Hatoum faz-nos lembrar de Proust, se a construçăo de uma personagem como Domingas, invariavelmente, remete-nos à Félicité, do conto "Um coraçâo simples", de Flaubert, também evidente é a relação de homenagem que principalmente Relato tem estabelecida com As mil e uma noites. E, nesse caso, cabe lembrar que o estabelecimento de relaçôes com uma literatura além do cânone europeu é um dos preceitos dos descentramentos "pós-moderno". De modo 
geral, assim é que vai se construindo a escrita de Hatoum, apropriando-se das palavras de Eliot citadas por Perrone-Moisés: "năo meramente com sua própria geraçăo em seus ossos, mas com o sentimento de que o conjunto da literatura européia desde Homero, e dentro dela o conjunto da literatura de seu próprio país, tem uma existência simultânea e compóe uma ordem" (Perrone-Moisés, 1998, p. 30).

\section{REFERÊNCIAS}

ARRIGUCCI JR., D. [texto de orelha]. In: HATOUM, M. Relato de um certo Oriente. Săo Paulo: Companhia das Letras, 2004.

BENJAMIN, W. Sobre o conceito da história. In: Magia e técnica, arte e política: ensaios sobre literatura e história da cultura. Trad. Sérgio Paulo Rouanet. Săo Paulo: Brasiliense, 2012.

BORGES, J. L. O informe de Brodie. Săo Paulo: Companhia das Letras, 2008.

COSTA LIMA, L. "O romance de Milton Hatoum". In: . Intervençōes. Săo Paulo: EdUSP, 2002.

FRANCISCO, D. L. A ficçâo em ruínas: Relato de um certo Oriente, de Milton Hatoum. 122 f. Dissertaçăo (Mestrado em Literatura Brasileira) - Programa de Pós-graduaçăo em Letras: Estudos Literários. Faculdade de Letras da Universidade Federal de Minas Gerais, Belo Horizonte, 2007.

HALBWACHS, M. A memória coletiva. Trad. Laurent Léon Schaffter. Ediçōes Vértice: São Paulo, 1990.

HATOUM, M. Dois irmáos. Săo Paulo: Companhia das Letras, 2000.

HATOUM, M. Relato de um certo Oriente. Sáo Paulo: Companhia das Letras, 2004.

HATOUM, M. Cinzas do Norte. Săo Paulo: Companhia das Letras, 2005.

PERRONE-MOISÉS, L. Altas literaturas: escolha e valor na obra crítica de escritores modernos. Săo Paulo: Companhia das Letras, 1998.

PERRONE-MOISÉS, L. Mutaçôes da literatura no século XXI. Săo Paulo: Companhia das Letras, 2016.

SANTIAGO, S. Autor novo, novo autor. Jornal do Brasil, Rio de Janeiro, 29 abr. 1989.

SANTIAGO, S. Nas malhas da letra: ensaios. Rio de Janeiro: Rocco, 2002.

SÜSSEKIND, F. Livro de Hatoum lembra jogo de paciência. Folha de S. Paulo, Sáo Paulo, 29 abr. 1989. 